\title{
Os concursos de beleza, disputas de israelidade
}

Beauty contests, Challenging Israeliness'

Keren Mazuz

Doutora em antropologia médica kerenmaz@gmail.com

Tradução: Mara Rúbia Sant'Anna

Revisão: Daniela Novelli

\footnotetext{
${ }^{1}$ Les concours de beauté, enjeux de l'israélianité. Publicado inicialmente em francês pela Revista Ethonologie Française, ano XLV, vol. 2, 2015, p.323-362. Autorização de tradução por Maria Vlachou responsável do Serviço de Revistas de Presse Université de France, editora da revista Ethonologie Française, em 15 de março de 2016. Acordo de tradução e publicação pela autora do texto, senhora Keren Mazuz, em 11 de março de 2016.
} 
Os concursos de beleza, disputas de israelidade

Beauty contests, Challenging Israeliness

Keren Mazuz

\section{Resumo}

A comparação de dois concursos de beleza "Rainha da Beleza de Israel" e "Miss AsiaIsrael", que ocorreram em 2006 permite descrever Israel em sua cotidianidade. Por meio deles, transformações sociais $\mathrm{e}$ culturais mais profundas se fazem visíveis. Cada espetáculo gera imagens e narrativas essenciais relativas ao que são ou deveriam ser as mulheres israelitas e, portanto, exprime o que deve ser a própria nação. Essa comparação revela que os dois concursos estão inscritos na ordem social da nação e propõem diferentes modelos de israelidade encarnados na exibição do corpo feminino.

Palavras- chave: concurso de beleza, corpo feminino, nacionalismo, evento público, Israel.

\begin{abstract}
In this article, I compare the "Israeli Beauty Queen" 2006 contest and "Miss Asia-Israel" 2006 contest as public events describing everyday Israel. Comparing both contests reflects the wider social and cultural transformations Israel is facing. Each pageant produces dominant imagens and narratives about whom and what 'Israeli' women are and should be while simultaneously narrating who and models of Israeliness embodied through the display of the female body.
\end{abstract}

Keywords: beauty pageants, female body, nationalism, public events. Israël 


\section{Introdução}

Dois concursos de beleza aconteceram em Israel na mesma semana do mês de março de 2006; 21 de março, o concurso "Rainha da beleza de Israel" (RBIsraël), e em 25 do mesmo mês "Miss Asie-Isräel" (MAsieIsraël). Sem considerar a idade, as medidas de cintura e a condição de solteira requeridas para o concurso, o único quesito exigido para o RBIsraël era a cidadania israelense. Desde seu lançamento nos anos 1950, quando não tinha mais que 20 candidatas, o concurso, que se mantém anual, é retransmitido para a televisão ao vivo. Por outro lado, o concurso MAsieIsraël contou com quinze imigrantes estrangeiras - provindas dos serviços assistenciais representando três países diferentes: Nepal, Índia e as Filipinas. Contudo, as candidatas indianas, que eram cidadãs judias-israelenses, não provinham dos mesmos setores. $\mathrm{O}$ concurso ocorreu, naquele ano, pela primeira vez, em um teatro público perto de Tel Aviv.

Comparando os dois concursos, este artigo procura descrever a vida cotidiana de Israel. Os concursos de beleza são lugares privilegiados para observar os mecanismos de fabricação de sentidos e onde as diferentes concepções culturais e sociais de israelidade relativas ao corpo feminino são expostas de maneira tangível. A comparação dos dois concursos de beleza reflete as transformações sociais e culturais mais proeminentes que Israel enfrenta. Neste lócus são negociados de fato diferentes modelos de israelidade, encarnados na exibição dos corpos femininos, que ligam os dois concursos à ordem social da nação.

Os concursos de beleza são somente mais uma instituição, entre outras, de apropriação das mulheres e de seus corpos com fins nacionalistas. Se oferecendo como espaços de pureza, de tradição e de moralidade, as mulheres e seus corpos tornaram-se símbolos nacionais que contribuem para salvaguardar o Estado (YUVAL-DAVIS; FLOYA-ANTHIAS, 1989). Contudo, os concursos de beleza engajam, igualmente, "as culturas locais e globais, étnicas e nacionais, nacionais e internacionais assim como as estruturas de poder em seus aspectos tanto mais triviais quanto vitais" (COHEN; WILK; STOELTJE, 1996, p. 8).

Porque ele estrutura as diferenças em uma ordem nacional homogeneizante, o concurso RBIsraël contribui para reafirmar as fronteiras nacionais. Por meio de imagens 
muito claras, despojadas de toda referência às tensões sociais e aos conflitos que elas trazem, o concurso propõe um modelo de israelidade fechado nele mesmo. Por contraste, exibindo uma diversidade étnica, racial e cívica e apresentando candidatas de diferentes países da Asia tornadas parte interessante do cenário israelense, o concurso MAsieIsraël estende as fronteiras nacionais. Essa extensão faz do concurso uma experiência global, e coloca em cena o multiculturalismo da israelidade. Se colocando a serviço como um espelho que amplia a imagem ${ }^{2}$, o MAsieIsarël oferece uma alternativa à RBIsraël e à homogeneidade da ordem nacional que ele veicula. Se destaca desta comparação por meio da qual o corpo feminino, a extensão do horizonte e do imaginário culturais israelenses, representa uma opção possível. Falando teoricamente, a estranheza torna-se de fato uma necessidade e uma fonte para o desenvolvimento interno de todo grupo homogêneo.

Os dois concursos podem ser apreendidos como eventos públicos (HANDELMAN, 1988, p.9), isto é, como suportes de comunicação capazes de transmitir aos participantes versões da ordem social em termos simbólicos relativamente coerentes. Assim, os concursos de beleza não são simplesmente a expressão de uma cultura de massa comercial onde se acumulam práticas disciplinares da feminilidade e da nacionalidade (BANET-WEISER, 1999), são também eventos que visam intencionalmente o horizonte da sociedade. O desenrolar de um concurso de beleza permite analisar as possibilidades que se oferecem para negociar ou descartar este ou aquele horizonte. O concurso é uma forma culturalmente concebida conforme uma trama programática conectada à vida cotidiana, e se verá aqui que cada concurso propõe uma maneira diferente de israelidade - real versus potencial.

Após uma breve descrição do sistema de cuidados às pessoas idosa, que está na base do recrutamento de apoio às famílias asiáticas e que constitui o contexto do concurso MAsieIsraël, descreverei e compararei os dois eventos. Metodologicamente, a pesquisa está fundamentada no exame da ordem interna dos concursos e como se concretizam no palco. Os concursos são espetáculo, performance pública, onde todos os tipos de comunicações verbais e não verbais são repetitivamente formuladas,

\footnotetext{
${ }^{2}$ N.T. Os espelhos côncavos ampliam os objetos observados, enquanto o convexo amplia o campo de visão. Na metáfora que a autora produz em sua argumentação, o espelho que se aplicaria neste caso seria o convexo, que sem ampliar o objeto, permite vê-lo por outras dimensões.
} 
constituídas e difundidas. Sendo incorporadas essas significações na ação mesma, o recurso ao nível verbal torna-se menos necessário. A observação dos concursos permite colocar em evidencia o papel do gênero tal como encarnado na configuração de pertencimento e de alteridade em Israel. Ironicamente, as normas corporais relativas às mulheres trabalhadoras estrangeiras não impediram a publicidade do concurso nem a exibição dos corpos.

\section{O fluxo migratório dos cuidadores familiares}

Desde o meio dos anos 1990, Israel tornou-se o pais anfitrião de grandes quantidades de trabalhadores estrangeiros, não judeus, vindos especialmente da Asia e do Leste Europeu (BARTRAM, 1998), que não podem demandar a cidadania local. Inicialmente, estes trabalhadores deviam substituir os trabalhadores palestinos dos territórios ocupados, aos quais, após a eclosão da primeira Intifada de 1987, o acesso à Israel era sistematicamente recusado. Em razão da falta de mão de obra, particularmente na agricultura e na construção civil, tornou-se necessário recorrer às agências de locação de trabalhadores imigrantes.

O setor de cuidados às pessoas idosas começou, então, a se desenvolver em consequência não esperada da dominação das agências responsáveis pelas migrações de trabalhadores. Em virtude da lei Nursing Care de 1988, os cidadãos israelenses que não podem se ocupar pessoalmente de ao menos uma das cinco praticas corporais de base (comer, se vestir, caminhar, se lavar e fazer sua higiene pessoal) são passíveis de um benefício: a ajuda permanente diária; eles podem, portanto, pleitear a ajuda governamental, uma vaga num asilo ou, ainda, uma assistência à domicílio, fornecida por trabalhadores migrantes.

Em razão da excelente reputação nos serviços domésticos e geriátricos, as agências escolheram, especificamente, promover o recrutamento de cuidadores familiares entre os migrantes provindos das Filipinas ${ }^{3}$. A dominação das mulheres

\footnotetext{
${ }^{3}$ Para saber maiores detalhes sobre os cuidados fornecidos por mulheres Filipinas no mundo ver: na Malásia, CHIN 1998; Los Angeles e em Roma, PARRENAS, 2001; em Hong Kong, CONSTABLE, 1997, em Taïwan, CHENG, 2003; ao Bahrein, LOUER, 2008. Por contraste com os outros locais, em Israel os filipinos tem por único trabalho cotidiano pacientes idosos. Trabalhar com não pacientes é considerado como trabalho ilegal e torna legítima a expulsão.
} 
filipinas no mercado israelense de cuidadoras é tal que sua identidade está sendo construída e codificada como uma categoria de emprego. Uma "filipina" tornou-se termo genérico para designar uma cuidadora não cidadã e não judia desejosa de assinar um contrato temporário de trabalho à salário baixo. Além disso, a autorização de trabalho de cuidadora é registrada no nome do paciente israelense. O que significa que quando o paciente falece, o visto torna-se inválido e o trabalhador um trabalhador ilegal, exposto à extradição imediata caso ele não encontre um novo paciente pela agência, e vice-versa.

A presença de cuidadores filipinos em Israel emite duas mensagens opostas. De um lado, essas mulheres não judias e não cidadãs são elogiadas pelo seu devotamento e, por outro, elas constituem uma ameaça para a visão governamental de uma sociedade judia endogâmica (MARZUZ, 2013) - um ameaça regulada e gerida por medidas interditando o reagrupamento familiar, os casamentos mistos e por restrições à gravidez. Todas as medidas que testemunham a ansiedade dos israelenses quanto a fecundidade das mulheres estrangeiras não judias.

Nestes últimos anos, as agências de trabalho temporário começaram a recrutar como cuidadoras trabalhadoras vindas do Nepal, do Sri-Lanka e da Índia. A despeito dessa mudança, subsiste a ideia de que as trabalhadoras asiáticas são as melhores cuidadoras. A ajuda assistencial é considerada em Israel como um trabalho temporário, que repousa sobre a inesgotável fonte de mulheres asiáticas em perpétua renovação.

\section{O concurso Miss Asie-Israël}

O concurso foi lançado por uma revista local chamada "Focal", publicação semanal que tem como público os trabalhadores imigrantes. Ele foi financiado por companhias de serviços aos trabalhadores estrangeiros, companhias internacionais de transporte e agências de viagens, cujos representantes foram nomeados como jurados. No público havia trabalhadores estrangeiros, de casais mistos de homens israelenses e de mulheres filipinas, algumas pessoas cuidadas pelas candidatas e amigos.

Às oito horas da noite, eu entrei no hall junto com o público. Após uma longa espera, as luzes foram apagadas e dois mestres de cerimônia filipinos fizeram sua entrada no palco sob os aplausos. Em inglês e tagalog, com alguns termos em hebreu, eles falaram de sua emoção e exprimiram sua gratidão a todas as pessoas e a todas as 
empresas que organizaram o evento. Após, o embaixador dos filipinos foi convidado a falar. Ele saldou a iniciativa e sublinhou o quanto era importante valorizar as trabalhadoras filipinas. Ele descreveu essas mulheres como de "bayanis noon", heroínas que se devotam tão bem à família como ao Estado. A presença do embaixador evidenciou a importância da comunidade filipina em Israel. Qualificar as trabalhadoras de heroínas as fazia trocar de posição e permitia-lhes sua identificação com a narrativa israelense de construção da nação, fundada sobre o corpo dos pioneiros e suas qualidades de devotamento.

Em seguida, os mestres de cerimônia anunciaram a primeira seção: "Miss Ilha Tropical". Uma por uma, quinze candidatas entraram então no palco sob os aplausos do público. Cada uma usava um maiô em cores e estilos diferentes. Como elas estavam colocadas umas ao lado das outras, o colorido dos maiôs acentuava a pele morena delas, seus cabelos, assim como as diferentes formas corporais e de peso. Ainda sobre o palco, posicionadas umas atrás das outras em círculo, todas saúdam o público. Os mestres de cerimônia agradecem-lhes e enquanto elas começam a deixar o palco, eles convidam um artista vindo das Filipinas para cantar algumas canções de amor em inglês e tagalog. Ao final do espetáculo, os mestres de cerimônia pedem às candidatas que retornem ao palco, a fim de anunciar que a vencedora do prêmio "Miss Ilha Tropical" era a candidata filipina de número quinze. Esta jovem vai ao centro do palco, sorridente e exaltada, para receber um presente e sua faixa de selecionada. Em seguida, as candidatas deixam o palco e um grupo de dançarinos de estilo indiano foi convidado para realizar sua apresentação.

Ao final do espetáculo, os mestres de cerimônia anunciam a segunda seção: o "Melhor traje típico". As candidatas, dispostas conforme o país de origem, estavam acompanhadas por homens vestidos a rigor, trazendo cada um a bandeira de seu país. Ao fundo, uma voz difundia as informações sobre o país, lugares turísticos e as características da comunidade nacional. O primeiro grupo a entrar no palco, com três candidatas, vinha da Índia. Na verdade, nenhuma era trabalhadora imigrante, e pareceume que todas tinham a cidadania israelense. O público repetia e gritava com ardor "elas não são verdadeiramente indianas", o que alimentava o rumor e a suspeita sobre a identidade étnica e nacional das três candidatas. Alguns suspeitavam que elas nasceram 
na Índia, sendo seus pais judeus e imigraram crianças para Israel, outros afirmavam que elas tinham nascido em Israel, de pais judeus com ascendência indiana. Após, um grupo de candidatas provenientes das Filipinas vestidas em trajes tradicionais chegaram no palco, seguido de outro grupo de candidatas do Nepal.

Para esta seção, cada candidata era chamada por seu número, seu nome e seu país de origem, e, então, convidada a se aproximar do centro do palco para responder às questões que lhes eram apresentadas. Todas as candidatas, vestidas em seus trajes típicos, se deslocavam calmamente para valorizar a singularidade de seu figurino. Os mestres de cerimônia apresentavam-lhes uma pequena questão pessoal. As questões variavam: "Qual a essência da mulher filipina?"; "O que poderia você fazer por sua comunidade?"; “Quais são seus grandes medos e suas maiores paixões?”. Somente as três candidatas indianas foram interrogadas em hebreu, o que somente fez exacerbar os comentários jocosos do público segundo os quais elas "não eram verdadeiramente indianas". Uma vez as questões terminadas, foi a vez de uma dança infantil. Os mestres de cerimônia convidaram em seguida as candidatas para a terceira seção: "O mais belo traje de gala". As candidatas assim vestidas em traje de gala no estilo ocidental desfilavam elegantemente, atravessando o palco conforme a ordem numérica, com o seu nome e seu país de origem. Assim que elas tomaram seus lugares, os mestres de cerimônia chamaram um cantor e dançarinos nepaleses.

Após esse episódio, os mestres de cerimônia anunciam os nomes das cinco finalistas. Novamente questões foram realizadas às finalistas pelos jurados e, na sequencia, um cantor vindo das Filipinas abrilhantou o espetáculo. Concluída a apresentação musical, os mestres de cerimônia convidaram as cinco candidatas finalistas e as demais a se colocarem ao lado deles. Eles proclamam as vencedoras das sub-categorias e em seguida a rainha da beleza "Miss Asie-Israël” 2006, cuja eleita era uma das mulheres judias israelenses representando o Estado da Índia. Todas as três foram coroadas e gratificadas com um certificado emoldurado. Um traje de gala foi oferecido à rainha, bem como uma joia e passagens aéreas para seu país de origem.

A declaração da vencedora foi acolhida pelos aplausos, mas também por protestos do público decepcionado com o fato de que a rainha escolhida não havia sido "verdadeiramente indiana", cada grupo esperando a vitória de sua representante. O 
público começava a se perguntar se os mestres de cerimônia não tinham feito algo errado. Contudo, a competição tinha terminado e, apesar de alguns protestos e manifestações do público, a Miss Asie-Israël foi coroada.

\section{O evento "Reine de Beauté d'Israël"}

Quatro dias mais tarde, o concurso "Reine de Beauté d'Israël" ocorria pela $56^{\mathrm{a}}$ vez. Eu observei a competição pela televisão, cuja a transmissão era ao vivo, apenas em hebreu, em horário nobre, no canal local. Essa competição foi lançada pela revista hebdomadária "To-Woman" e financiada por empresas israelenses bem conhecidas de produtos de beleza, de moda, de joias e de cosméticos, os quais designaram seus representantes como jurados. As condições de participação para essa competição são quatro: ter cidadania israelense, ter idade entre 17 e 24 anos, medir acima de 1,53 cm e ser solteira. As vinte candidatas deviam participar de seções de fotos em diferentes pontos turísticos do país antes de serem enviadas em viagem organizada para a Tailândia.

Figura 1 - Les Gagnantes du concours Miss Asie - Israël

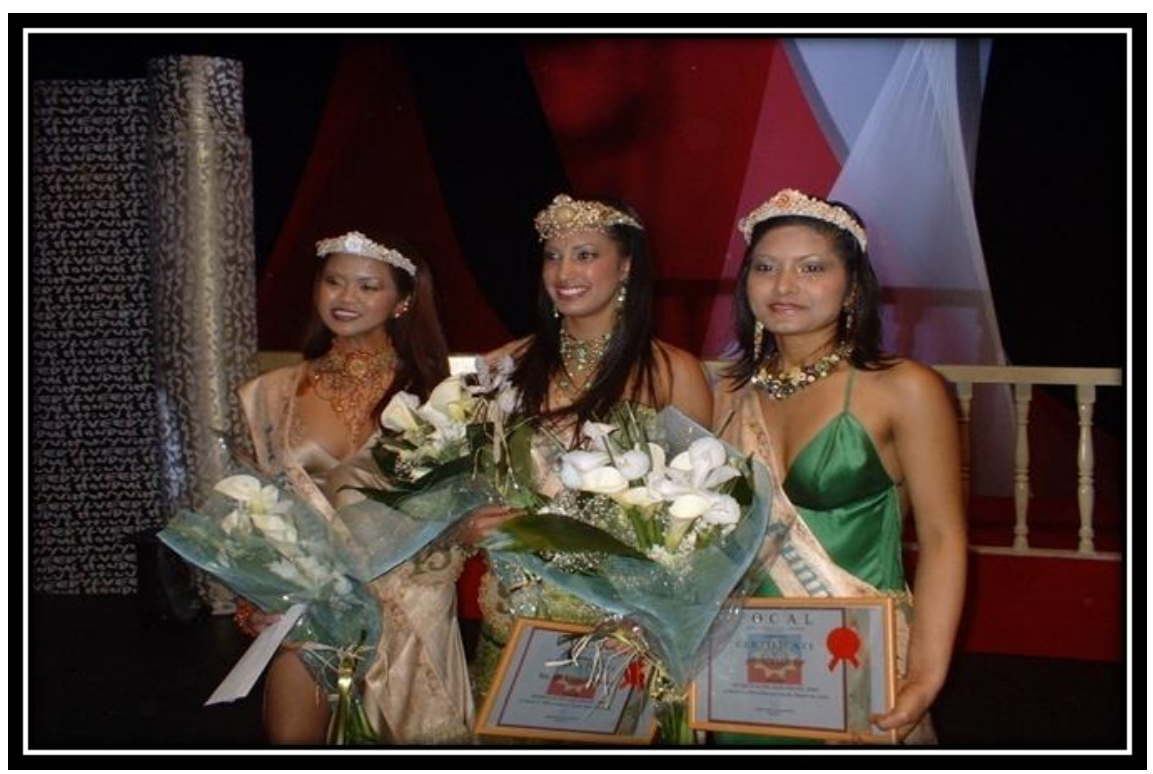

Photo du Jerusalem -Post, mars 2012

O evento RBIsraël foi iniciado com a entrada no palco de vinte candidatas acompanhadas do mestre de cerimônias. Todas tinham a pele clara, cabelos loiros e vestiam uma roupa de verão curta, fabricada por uma empresa israelense de moda, com o número fixado sobre os quadris. As 20 candidatas foram divididas em quatro grupos 
de tamanho parecido. Após, um vídeo produzido anteriormente exibiu quatro símbolos israelenses facilmente reconhecíveis: o kibutz ${ }^{4}$ o Muro das lamentações, o falafel ${ }^{5} \mathrm{e}$ algumas danças folclóricas. Cada filme continha trechos de documentários diversos mais antigos.

As cinco candidatas do primeiro grupo tinham sido enviadas ao kibutz, símbolo maior da fundação da nação. Elas foram filmadas enquanto acompanhavam um parto, coletavam ovos de galinha e cavavam sulcos nos caminhos do kibutz; o segundo grupo foi filmado enquanto orava em uma das fendas do Muro; se via o terceiro grupo aprendendo a fazer falaféis em Jerusalém e o quarto grupo foi filmado estudando danças folclóricas e canções israelenses tradicionais. Em cada filme, as candidatas se apresentavam individualmente, indicando nome, idade, cidade de moradia, hobbies e ambições. As candidatas não responderam nenhuma questão durante o concurso. A despeito das controvérsias e das tensões sociais levantadas recentemente pelos símbolos escolhidos ${ }^{6}$, tudo foi feito para que, por meio do corpo feminino, o concurso apresentasse uma performance homogeneizante, no qual o silêncio das candidatas mão faziam senão reforçar essa estratégia de se evitar qualquer subjetividade. O sentido primeiro desses símbolos é o da unificação: qual que fosse a origem étnica, as mulheres tinham o dever de sustentar a narrativa da homogeneidade nacional.

Entre os clips, houve espetáculos de cantos e danças realizados por artistas israelenses; as candidatas foram apresentadas com três outros trajes: maiôs fabricados por uma empresa local de produtos de moda, e dois modelos de vestidos criados por designers de moda israelenses. Apesar da troca de modelos dos vestidos de gala, a uniformidade dominava dentre as candidatas, por exemplo os maiôs eram todos

\footnotetext{
4 Pequena comunidade israelense economicamente autônoma com base em trabalho agrícola ou agroindustrial, caracterizada por uma organização igualitária e democrática, obtida pela propriedade coletiva dos meios de produção e da administração conduzida por todos os seus integrantes em assembleias gerais regulares.

${ }^{5}$ Falafel é um salgadinho originário do Oriente médio. Consiste em bolinhos fritos de grão-de-bico ou fava moídos, normalmente misturados com condimentos como alho, cebolinha, salsa, coentro e cominho. Típico da cozinha israelense. Veja: http://www.saboresdeisrael.com.br/receitas/receita-de-falafelisraelense.html [Nota da tradutora]

${ }^{6}$ Movimentos sociais como Women of the Wall (as Mulheres do Muro) que militam para que as mulheres sejam autorizadas a orar diante do Muro da Lamentações, desafiam as autoridades ortodoxas; se debate também o papel social do kibutz desde que estes foram privatizados; se interroga enfim sobre a proveniência - israelita ou árabe- do falafel. [Nota do tradutor do original em inglês, Sra. Anne Gotman).
} 
brancos. O momento do desfile em maiô deixava ver a brancura e a delicadeza da pele das candidatas, bem como sua magreza e a firmeza de seus corpos.

Em seguida, dez finalistas foram escolhidas. A seleção tinha sido realizada pelo júri, juntamente com o público que estava na sala ou em sua casa e que tinha enviado mensagens escolhendo sua candidata favorita, o que influenciava a seleção das finalistas pelos jurados. Um entre eles foi então convidado a subir ao palco e anunciar as dez semi-finalistas. Após uma pausa com músicas, um outro jurado anunciou as seis finalistas, que se apresentaram em vestidos brancos super sofisticados, semelhantes aos vestidos de noiva. Destas seis candidatas, foram selecionadas então quatro, que correspondiam às sub-categorias seguintes: "a jovem israelense", a "Rainha da Graça", "A jovem beleza" e a "Preferida do Público". Convidados a premiar as duas primeiras colocadas, os jurados lhes ofereceram uma coroa, a faixa e um buquê de flores. As seis classificadas deveriam representar Israel em diferentes concursos de beleza internacionais.

Após um intervalo publicitário e algumas canções de cantor israelense, o redator chefe da revista que organizou o concurso foi convidado a coroar a vencedora final. Sob os aplausos do público, a rainha da beleza do ano precedente passou então a coroa de sua cabeça para a da vencedora da noite.

\section{Três eixos de comparação}

A comparação e a análise dos esquemas de concursos colocam em evidência três temas: a estrutura do evento e sua lógica, a maneira pela qual o evento se distingue da vida cotidiana e a participação do público. Cada um permite observar a forma pela qual estes eventos são construídos em relação à experiência e ao imaginário de israelidade.

\section{A estrutura do evento e sua lógica}

Durante o desenvolvimento do concurso RBIsraël, as candidatas estavam organizadas em grupos de cinco. Depois, dez semi-finalistas foram escolhidas, sendo reduzidas em seguida à seis candidatas. A estrutura do evento foi concebida de maneira a fundir os indivíduos em um grupo coletivo coerente, sendo a manifestação de um 
símbolo chave da sociedade israelense (KATRIEL, 1991, p. 13). Esse símbolo oferece uma imagem de ordem e de maneiras socialmente valorizadas de ação. A cristalização da unidade das candidatas no seio do concurso começou mesmo antes que a competição tivesse iniciado. Elas viajaram juntas para a Tailândia, uma paisagem estrangeira que as constituiu como um grupo unificado a ponto de ser dotado de um alto grau de coesão, com fronteiras claramente marcadas, fortemente integrada e indiferenciada em termos de valores sociais.

Foto 2 - La Reine de beauté d'Israël en 2011

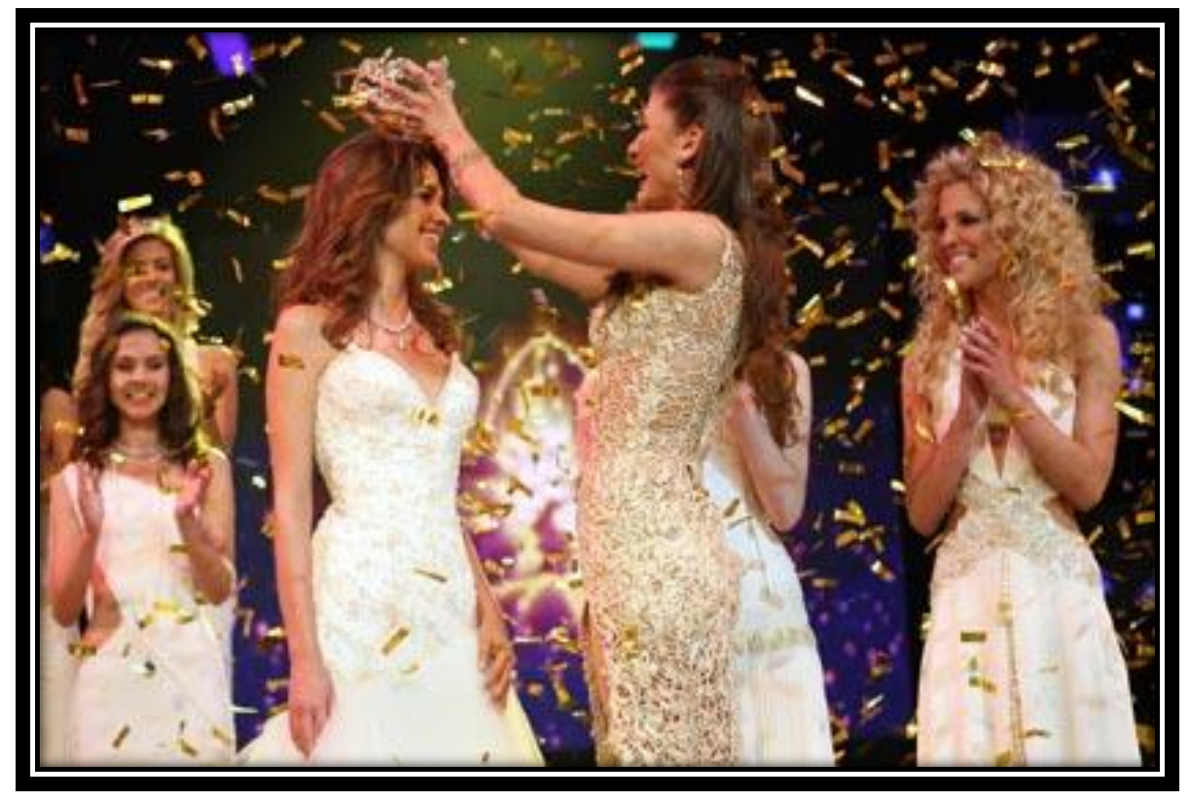

Fonte: http://www.ynet.com.il/articles/0,7340,L-3230633,00.html\#n Acesso em: 17 de fevereiro de 2011

Além disso, cada um dos quatros símbolos nacionais cristaliza a capacidade de fazer surgir um sentido de coletividade e de solidariedade: o muro das lamentações encarna um grupo formado para a oração, a vida no kibutz é fundada sobre o compartilhar e a comunidade, e as danças folclóricas são de rodas onde se dá as mãos. $\mathrm{O}$ uso exclusivo do hebreu, os espetáculos israelenses e os apresentadores, bem como os trajes fabricados em Israel, propõem o partilhar de uma experiência, seja das candidatas ou do público. O concurso RBIsraël inclui assim elementos bem estabelecidos da nacionalidade israelense, por meio de interações sociais específicas e a manipulação simbólica dos corpos das candidatas. 
Essa apresentação de maneira abertamente unificada eclipsa as diferentes individualidades e os conflitos escondidos nos quatro símbolos escolhidos. RBIsraël amalgama de maneira não crítica a realização individual com a constituição de uma comunidade. E ainda, o concurso RBIsraël facilita a conexão entre o passado (através da incorporação de documentários) e o presente, assim como se dá entre o espaço do concurso e a sala do espectador diante da televisão. Ele oferece aos participantes um reflexo da ordem social e cria a ligação entre narrativas, símbolos, boas ações, emoções e cidadania. Este evento não deixa qualquer lugar ao luxo da diversidade e do desconhecido.

Por contraste, no concurso MasieIsraël, as quinze candidatas eram julgadas segundo três categorias em função de seu estilo de roupa, o que permite a expressão de uma subjetividade. Durante a seção "Miss Ilha Tropical”, todas as candidatas exibiam maiôs coloridos expondo suas diferenças de peso, de tamanho e cor de pele. O título escolhido "ilhas tropicais" conferia aos corpos expostos uma ideia de exotismo, estranha à paisagem israelense. As duas seções seguintes introduziram um tensão entre o nacional e o individual. Durante a seção "melhor traje típico", as candidatas traziam um traje diferente daqueles de suas compatriotas, mesmo que elas fossem trazidas como membros de um mesmo grupo nacional. A cada mulher, individualmente, foram propostas questões sobre seus sonhos, paixões, seus medos, seus amores e seus hobbies, contrastando com as vozes gravadas das candidatas de RBIsraël, que nada falaram sobre o palco. Apresentadas em vestidos de gala, as candidatas puderam favorecer sua aparência individual. Por meio do uso da multilinguagem e das áudio-experiências culturais, a transição de uma categoria à outra devia produzir um sentido inesperado. A cada vez o espetáculo contextualizava as diferenças da subjetividade feminina das candidatas. Por meio das três seções, as competidoras se tornaram atrizes modernas, depois tradicionais e, por fim, inscritas na economia global. Mesmo a rainha escolhida foi uma surpresa, tanto para as candidatas como para o público. Assim, o concurso MAsieIsraël ofereceu uma celebração da alteridade e da diferença, no qual nada é familiar nem conhecido antecipadamente. Desta maneira, ele revela também as desigualdades no interior de um grupo de estrangeiros. 


\section{A distinção do evento com a vida cotidiana}

No concurso RBIsraël não se faz distinção entre a vida cotidiana e o evento. $\mathrm{O}$ mundo exterior está integrado na estrutura interna do evento, de modo que os corpos das candidatas constituem uma extensão direta da ordem social que prevalece além do espaço-tempo do concurso. A integração da ordem social foi alcançada pela fusão dos quatro símbolos bem conhecidos de Israel, sem explicações sobre as razões de terem eles sido escolhidos, nem sobre as tensões sociais das quais eles são objetos. As gravações em vídeo utilizaram os corpos das candidatas para forjar os liames visuais entre os símbolos e a vida cotidiana, entre o passado e o presente. A mulher israelense solteira, uniformizada, torna-se a tela final sobre a qual se apresenta e se reflete a narrativa nacional de israelidade.

Em comparação, MAsieIsrael fixa uma distinção com a vida de todos os dias. Durante o evento, as trabalhadoras estrangeiras tornaram-se candidatas de um concurso de beleza, em vez de cuidadoras. Sobre o palco, elas abandonaram sua aparência cotidiana para vestir maiôs, trajes típicos e vestidos de gala. O universo imaginário que circula no concurso MAsieIsraël gera uma ordem de representações ligando diferentes imagens femininas entre si. Começa com a imagem da mulher enquanto corpo, mergulhando-a em seguida em sua comunidade étnica, para terminar com uma mulher transformada pela modernidade em figura transcendente, pronta para ser lançada no cenário global. Essas mulheres puderam também se exprimir em sua língua natal, não presente em sua vida cotidiana. Assim, esse concurso permite a estas mulheres ultrapassar o seu papel de cuidadoras, indo além das fronteiras da cotidianidade israelense, em direção a outros horizontes culturais.

\section{A participação do público}

Por meio suspiros e aplausos, o público do concurso MasieIsraël exprimiu sua decepção e suas dúvidas quanto ao evento. As candidatas indianas suscitaram contestações, embaraços e incertezas dentre a audiência que fazia saber alto e forte que “elas não são verdadeiramente indianas". Um paradoxo surgiu: quem é a mulher judiaisraelense que representa a Índia? Seriam elas realmente indianas ou fariam "como se fossem" apenas pelo concurso? 
O concurso torna-se uma metáfora e o "elas não são verdadeiramente indiana" é utilizado como metalinguagem7 para dizer que "isso é um jogo" (HANDELMAN, 1988, p. 69), sublinhando as condições de incerteza, desde que o fenômeno é uma coisa - indiana - e simultaneamente outra - israelense. Ao mesmo tempo, o concurso pode ser totalmente indiano e israelense, ou melhor, nem um nem outro. A condição de jogo autoriza a emergência da contradição e da negação. Mesmo quando a candidata indiana foi declarada "Miss Asie-Israel”, este paradoxo não foi resolvido.

Regular um concurso de beleza como um jogo implica um elemento de incerteza, eventual discussão de sua validade e seu estatuto. Este elemento denota a fluidez do concurso MAsieIsrael, cujas realidades podem ser objeto de alteração ou de dúvida. O jogo organiza um espaço para a diferença e a multiplicidade, no seio da qual as jovens mulheres judias israelenses podem tornar-se rainhas da beleza.

Em comparação, o concurso RBIsraël produz um evento que é supostamente identificador de símbolos bem conhecidos, por meio dos quais a nação representa a si própria. $\mathrm{O}$ evento tem uma dimensão nacional; ele é transmitido pela televisão com a mesma pompa dedicada à comemoração do Jour du Souvenir8 e às cerimônias do Dia da Independência. $O$ concurso se transforma assim em uma performance cênica elaborada para uma audiência nacional. Televisado, o concurso de beleza permite que os lares israelenses participem de uma experiência coletiva. Enviando mensagens (msm) como num reality-show, o público filtra as candidatas e, assim sendo, desenham as fronteiras do grupo nacional sobre o corpo feminino. Com suas vestimentas idênticas, sob a mesma cadência e em grupo, as candidatas se replicam; todas são boas para se tornarem a "rainha israelense da beleza", destinadas a representar o Estado nos concursos internacionais de beleza.

Associando a sala do espetáculo e o lar, o evento e a realidade cotidiana, o concurso cria uma lógica burocrática de filtragem e de separação assumida pelos telespectadores e os jurados. Por meio de um corpo feminino unificado, o concurso de beleza serve à ansiedade da nação israelense diante de seu desejo de estabilidade por sua

\footnotetext{
${ }^{7}$ No original em francês méta-message, que traduzido literalmente seria metamensagem, um neologismo. Todavia o sentido de metalinguagem adequa-se a proposta da frase.

${ }^{8}$ Data que lembra o genocídio cometido do povo judeu e sua luta durante a Segunda Guerra Mundial, comemorado no dia 27 de Nissam (mês do calendário hebreu, próximo a abril), conhecido como Yom Ha Shoah - Dia pela Shoah e o heroísmo. [N.T.]
} 
imagem de nação coerente, com fronteiras seguras. Em 2001, Miss Israel declarou que no concurso de Miss Universo ela tinha usado uma "roupa com um colete à prova de balas incrustado de diamantes" [WILKINSON, 2001]. Por meio dessa declaração, ele fazia eco à questão da segurança sob a qual Israel foi confrontada e estampava sua bravura como uma virtude nacional e social, para a qual todos os israelenses são convidados a aderir. Em uma sociedade altamente estratificada e dividida etnicamente, o concurso RBIsrael tornou todos os judeus israelenses iguais, tornando-os consumidores, observadores, espectadores dotados de valores comuns, e mesmo portadores do direito de julgar o corpo feminino e, ainda, de unificar a nação por meio dele.

\section{Encarnar a israelidade por meio da estética}

Cada concurso tem uma forma culturalmente determinada. O concurso RBIsraël que se expressa como o reflexo da ordem social, conduz a um modelo bloqueado de israelidade que, por autorizar as performances sociais, repousa sobre uma ordem burocrática. De maneira que todas as candidatas tinham a cidadania israelense, os critérios de participação estavam suficientemente claros para prevenir todos os incômodos que a diferença e a diversidade são suscetíveis de desencadear. Através desse concurso Israel se encontra construída como um enclave desconectado, não somente de seu espaço geográfico, mas também dos fenômenos que se desenvolvem no país, como o caso dele possuir um crescente número de mulheres trabalhadores de origem imigrantes que são excluídas desse concurso. Nestes muros, não há lugar senão para a auto referência dos símbolos nacionais e das categorias burocráticas. A precedente rainha da beleza pode passar a coroa de sua cabeça a nova eleita de cada ano, e o discurso nacionalista pode difundir suas imagens selecionadas e sua estética. Testemunha o fato que sobre o total de cinquenta e cinco concursos realizados, se fez apenas seis rainhas da beleza de origem oriental (Séfarade-Mizrahi), uma israelita árabe (em 1999), uma outra de origem etiópica (em 2013) e seis outras que são de origem mista. Todas as outras, ou seja, quase cinquenta rainhas, são de origem Ashkenaze, cidadãs, pele clara e judia foram compactadas para representar a nação. As mulheres ashkenaze encarnam as imagens nacionais dessas que são e que deveriam ser as mulheres israelenses; simultaneamente elas narram o que a nação deve ser. É produto da 
política israelense de assimilação (melting pot) que, para construir um estado-nação homogêneo, confunde as imigrantes judias Séfarade-Mizrahi com o arquétipo Ashkenaze europeu (SHOHAT, 1999).

Em comparação, o concurso MAsieIsraël oferece a alternativa de um evento multicultural orientado para o continente asiático. O olhar de Israel volta-se para o exterior, a estrutura do concurso não está fundada sobre um critério de cidadania, mas sobretudo sobre os reencontros corporais criadores de contradições e de tensões. O concurso vai além das fronteiras disso que constitui a israelidade, e permite valorizar a multiplicidade e a diversidade. Ele oferece um modelo aberto e flexível de israelidade onde a descoberta de si toma lugar diante do outro e onde as interações lúdicas podem emergir.

Esse concurso indica que a expansão do horizonte de israelidade por meio do corpo feminino é possível. Será apenas num contexto multicultural que uma mulher indiana, judia, oriental pode passar diante de outras e tornar-se a rainha da beleza. Assim, a estraneidade ${ }^{9}$ é sobretudo um fonte para as trabalhadores estrangeiras que oferecem às famílias judias e aos idosos uma possibilidade: depender de mulheres estrangeiras para sobreviver com dignidade. Se pode mesmo estabelecer relação com o livro $^{10}$ de Ruth, a jovem Moabita ${ }^{11}$, no qual a nora estrangeira e não judia de Noemi casou-se com Boaz tornando-se a bisavó do Rei Davi. Seu casamento com Boaz estendeu as fronteiras do grupo endógamo de Israel a ponto de torná-lo um reinado.

Artigo recebido em Maio de 2016. Aprovado em Junho de 2016 DOI:http://dx.doi.org/105965/1982615x09182016004

\footnotetext{
${ }^{9}$ S. f. \| situação jurídica de estrangeiro no pais em que está domiciliado. F. lat. Extraneus. [N.T.]

${ }^{10}$ Um dos livros do Velho Testamento, primeira parte da Bíblia. Que narra a história de uma senhora chamada Ruth e sua fiel nora Noemi que abandona seu povo Moabita para ir para Israel com a sogra. Lá ela conhece um novo marido e, mesmo estrangeira, por sua fé a Deus e fidelidade à Noemi, a jovem Ruth é admitida no povo judaico. Ver em https://www.bibliaonline.com.br/acf/rt/1 [N.T.]

${ }^{11}$ Os moabitas foram um povo nômade que se estabeleceu a leste do Mar Morto por volta do século XIII a.C., na região que mais tarde seria chamada de Moabe. Eram aparentados com os hebreus, com os quais tiveram vários conflitos. Foram combatidos e subjugados por Davi, rei de Israel. Os moabitas readquiriram a independência depois do Cisma das doze tribos hebreias. Voltaram-se ao nomadismo e tempos depois Moabe foi anexado como parte da província romana da Arábia. [N.T.]
} 


\section{Referências}

BANET - WEISER Sarah, 1999, The Most Beautiful Girl in the Word: Beauty Pageants and National Identity, Oakland, University of California Press.

BARTRAM David, 1998, "Foreign Workers in Israel: History and Theory", International Migration Review, 32: 303-325.

CHENG SHU-JU Ada, 2003, "Rethinking the globalization of domestic service: Foreign domestics, state control and the politics of identity in Taiwan", Gender $e$ Society, 17, 2: 166-186.

CHIN Christine, 1998, In Service and Servitude, New York, Columbia University Press.

COHEN Colleen B., Richard WILK and Beverly STOELTJE (eds.), 1996, Beauty Queens on the Global Stage: Gender, Contests and Power, London, Routledge.

CONSTABLE Nicole, 1997, "Sexuality and Discipline among Filipina domestic Workers in Hong-Kong", American Ethnologist, 24, 3: 539-558.

HANDELMAN Don, 1998, Models and Mirrors, Towards an Anthropology of Public Event, New York, Berghahn press.

KATRIEL Tamar, 1991, Communal Webs: Communication and Culture in Contemporary Israel, New York, State University Press.

LOUER Laurence, 2008, “ The Political Impact of Labor Migration of Labor Migration in Bahrain", City \& Society 20, 1: 32-53

MAZUZ Keren, 2013, "The State of the Family: Eldercare as a Practice of Corporal Symbioses by Filipina Migrant Workers", in Fran Markowitz (ed.), Ethnographic Encounters in Israel: Poetics and Ethics of Fieldwork, Bloomington, University of Indiana Press $97-112$.

NAGY Sharon, 2008, “The Search for Miss Philippines Bahrain - Possibilities for Representation in Expatriate Communities" City \& Society, 20 1: 79-104.

PARREÑAS Rachel Salazar, 2001, Servants of Globalization: Women, Migration and Domestic Work, Redwood City, Stanford University Press.

SHOHAT Ella, 1999, The Invention of the Mizrahim", journal of Palestine Studies, 29, 1: $5-20$

YUVAL- Davis Nira and Floya Anthias (eds), 1989, Woman- Nation- State, London, Macmillan Press.

WILKSON Tracy, 2001 "Israeli Beauty Queen Will Be Dressed to the Mines", Los Angeles Times, retrieved from: http://articles.latimes.com/2001/May/06/news/mn-59997 $(13 / 8 / 13)$. 